\title{
Further Notes on the Golden Eagle in the Beechy Area
}

\section{By Dave Santy, Beechy}

Recent articles have focussed public attention on the prairie nesting of the Golden Eagle. I have, with others, observed Golden Eagle nests practically every season for the past forty years, in the roughlands area west of the elbow oi the South Saskatchewan River.

The nest is usually a large closeknit framework structure of sticks and mud built bracket-like into the south face of a steep cut bank and so strongly attached thereto that I have sat on one (after the nesting season was over), without fear of breaking it down. On two occasions, however, I found active nests that were built on tree protruding peak of a high promontory.

In $1953 \mathrm{I}$ observed three active nests in a 50-mile stretch along the river banks in this area: one in the Perrin Ranch southwest of Beechy; one in the Mason Ranch south of Demaine; the other in the Jones Ranch soutr of Lucky Lake. They were spaced about 15 miles apart. It would seem, therefore, that each nesting pair requires a large hunting range, and that this is recognized by others of its kind.

In an intensive search this yea: (1959) only one active nest was lo cated in the area mentioned above.

Farmers and ranchers generally in this district need have no quarrel with the Golden Eagles. Some, however, don't even know what they are and think them to be large harmful hawks. In the nests I have observed, the chief prey item has been the jack rabbit, with gophers and weasels also common. Sometimes a duck or other water bird is present, but I cannot remember seeing remains of barnyard fowl, insectivorous birds or grouse.

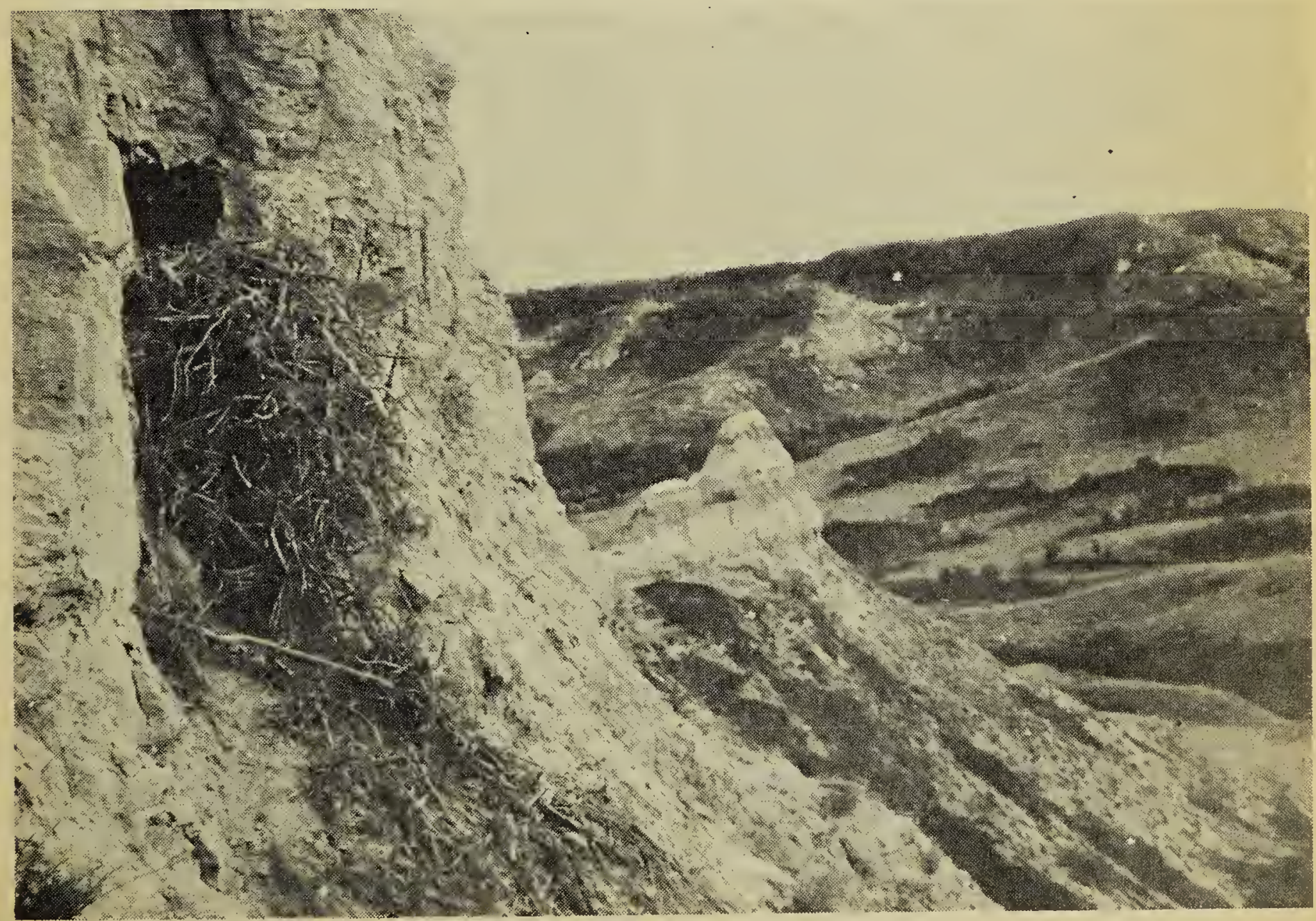

Photo by R. Fyte

Golden Eagles in a cliff-side nest in the Big Muddy Valley in a habitat very similar to that described by Mr. Santy at Beechy. 